Article

\title{
Subtraction: More than an Algorithm?
}

\author{
M. Mercedes Rodríguez-Sánchez ${ }^{1, *(\mathbb{D})}$, Ana B. Sánchez-García ${ }^{2}$ and Ricardo López-Fernández ${ }^{1}$ \\ 1 Department of Didactics of Mathematics and Experimental Sciences, Faculty of Education, \\ University of Salamanca, 37008 Salamanca, Spain; riclop@usal.es \\ 2 Department of Didactics, Organization and Research Methods, Faculty of Education, \\ University of Salamanca, 37008 Salamanca, Spain; asg@usal.es \\ * Correspondence: meros@usal.es
}

Received: 1 October 2020; Accepted: 30 October 2020; Published: 3 November 2020

\begin{abstract}
One of the aims of compulsory education is for students to adequately handle basic maths, owing to its importance in their future professional and personal lives. However, mechanical knowledge of an algorithm may not be sufficient to train future citizens with critical and creative thinking if it is not accompanied by a comprehensive understanding of the concept. In this regard, existing research shows that a high percentage of students in primary education commit errors when they attempt subtraction. However, little is known about whether adults perform the same calculations correctly. In this context, 535 university students completed a questionnaire composed of 20 subtractions. The results showed that only one quarter of respondents performed the subtractions correctly. Analysis of error type showed that the most frequent mistakes corresponded to the systematic errors made by primary-level students. This may indicate that the types of errors committed during early learning persist over time, implying that subtraction may not have been adequately taught. New educational approaches and initiatives are required to encourage the teaching and learning of subtraction in a more reasoned and critical manner during early learning.
\end{abstract}

Keywords: subtraction algorithm; critical thinking; mathematical education

\section{Introduction}

Current educational trends hold that it is necessary to offer an education in which students can reason, face problems and difficulties and develop creativity and critical thinking. They need classroom training to live and work as citizens in a world where they will not encounter exact paths or solutions, or will have to make decisions that differ from the experts when they need to purchase life insurance, organise holidays or decide which house to live in [1-3].

However, elementary education continues to be dominated by classes that favour rote learning [4] which could be explained by the fact that most of the tasks that are conducted in the classroom come from textbooks which are mostly automated tasks [5-7]. The significant lack of understanding of basic maths is a circumstance that is accepted by the education community, while the continued use of algorithmic calculations remains a priority aim in the majority of countries worldwide. For example, subtraction tends to be considered, following rote learning, as a mechanical process that consists of applying algorithmic steps in the appropriate order [8].

However, subtraction involves more than applying an algorithm. It is not merely a rote learning and mechanical process, but rather includes a process of acquiring the algorithmic procedure and interpreting that procedure, which has to take into account when and how the algorithm is applied and what it means. The importance of the subject understanding the conceptual basis of the algorithmic process of subtraction has been described as essential in many studies (see [8-16]).

The evidence supporting the influence of numerical calculations beyond the school setting, where mathematics occupies an important position in contemporary society both in defining profiles 
associated with securing a certain employment position and opportunities for promotion at work [17], and the relationship between mastery of arithmetic operations and the attainment of goals in different fields [18], justify investigation of the state of development of basic maths among adults. For this reason, given the social importance of processes associated with numerical skills [19], there is a need to examine the results of subtraction operations performed by adults, focused on a very specific group of them-university students. Some studies suggest that many adults do not display adequate skills in situations related to the declarative knowledge underpinning mathematical procedures such as addition and subtraction [20] and have far-from-adequate estimation skills [21].

The aim of this study is to generate knowledge that can be applied to the training of future compulsory education professionals and currently practising teachers. The intention is to stress that algorithmic learning of subtraction only makes sense when it is effectively achieved, in addition to being located within a knowledge of the concept of subtraction that facilitates the understanding that the algorithmic mechanism must be considered from a perspective of reasoning and critical thinking. As such, the ultimate purpose of this study is to reconsider basic education, which in many cases tends to remain mechanical and rote, and to construct it as rational, critical and creative. Teachers have to construct arithmetic knowledge taking into account the rational conceptual understanding of arithmetic principles (see [22]).

In this context, the aim of this study is to analyse the errors that university students make when they perform subtractions. The results may help reflections to improve the learning of this and other mathematical operations, and to develop methodological approaches for this purpose.

\section{Theoretical Framework}

Subtraction is part of the basic maths that is learned in early education. The acquisition of subtraction knowledge takes place over several stages. First, from the initial years of infant education (up to the age of 6 years), children perform subtractions intuitively in situations that arise in their immediate environment. These are usually but not always simple calculations. Children's proposed solutions are not always correct. This learning can be facilitated in a natural manner, by using specific materials from the immediate environment in different ways as, for example, when children compare the candies they have between them or when they go up or down stairs (for more detail, see [23]). Some authors refer to this as informal mathematics (see [24,25]). The development of this informal mathematics is considered highly important as it forms the basis for more formal subsequent learning $[26,27]$.

The formal learning of subtraction is then developed during the primary education stages (6-12 years), based mainly on knowledge of the algorithm, in terms of both its conceptual framework-taking into account meanings related to the concepts of remove, lose, separate, take away, take, borrow, count, add or balance-and its procedural framework-taking into account the system of rules that permit the creation of a relationship between the conceptual level and the procedure in itself. This formal learning is mainly directed at correctly applying the algorithm and studying the errors made in implementing it (see [28-30]).

The study of errors has been the main focus of research related to learning subtraction. Brownell [31] published the first theoretical studies to examine these errors, arguing that they were committed due to certain routines that are learned during the initial process of teaching the algorithm, repeated without understanding and applied to practical situations to consolidate the learning of the procedure. These routines can only be useful if the structures underpinning the algorithmic content are visualised, are easy to teach and can be turned into efficient execution routines [32].

Therefore, to analyse subtraction errors, Brown and Burton [33] followed Gagne [34] and Resnick [8] in pursuing the hierarchical analysis tradition, and created a model for the discovery and diagnosis of misconceptions arising among students with the aim of offering teachers a mechanism that would go beyond error identification and explain why the student was making the mistake. In order for this automaticity to be possible, it was necessary to be able to represent the procedural skill via the required 
sub-processes, both incorrect and correct, and a mixture of both. This procedural framework consisted of two main parts: a conceptual one, representing the conceptual framework for the procedure, and an operational one, which consisted of the methods for executing the procedure. It was also necessary to take into account the relationships between the various error types. As many as 60 types of error were categorised based on an analysis of subtractions performed by 1325 students in primary education.

Although these aspects were investigated in more detail in several studies (see [35,36]), Lankford [37] and Ashlock [38] concluded that many erroneous results were due to failures in the process of executing the subtraction algorithm rather than carelessness; in other words, errors occurring during subtraction were more the result of using various incorrect strategies than of incorrect use of number facts. On this basis and influenced by theories of information processing [39] and cognitive psychology [40], Young and O'Shea [41] created a production system to analyse subtraction errors. This was a collection of rules involving the application of actions that would allow subtraction to be understood as a combination of several strategies [42,43]. The production system consisted of processing each column by following rules, involving first comparing, deducting and subtracting (rule 1), then calculating the difference (rule 2) and finally moving to the next column (rule 3). This analysis led to the classification of erroneous responses in three error categories [41], where some errors could not be categorised: number facts (in which correct borrowing had taken place and the result differed from the correct one by a small amount, such as $9-3=7$ ); algorithmic (Borrow when $<$ Take smaller, Always borrow, $\mathrm{S}>\mathrm{M} \rightarrow 0$, One $\rightarrow 10$, Add Column 2), or zero pattern $(0-\mathrm{N}=\mathrm{N}$, $0-\mathrm{N}=0, \mathrm{~N}-\mathrm{N}=\mathrm{N})$.

At that time, it was considered that failures in procedural skills in multicolumn subtraction might be fundamentally due to slips; that is, failures owing to the performance or carelessness of the student, unstable over time, or to bugs, that is, failures in competencies that reflected skill-related errors or disturbances to the correct procedure, stable over time, which also helped to describe the failure. Progress appeared necessary, and would involve investigation of how students acquired these errors, how long they persisted for and why they disappeared, in addition to analysis of whether-as had been believed until that time- the only possible errors were systematic (procedural) and non-systematic (unintentional carelessness). This gave rise to repair theory [44,45], which took previous studies into account and was based on the idea that when a student reaches an impasse during the performance of the subtraction procedure, as they cannot take another step forward, they will apply a repair-a small but sufficient variation in the resolution of the subtraction to complete it, in order to overcome the step, move forward and complete the result, normally with little success in terms of achieving the correct response. For example, if a student has to borrow at zero and reaches an impasse because they cannot decrement a zero, they might use the solution of simply not borrowing across $(403-56=357$, error Stop Borrow At Zero). In fact, different repairs may be applied to the same dead end. So, for example, when a student finds a column with a zero at the top and the corresponding bottom is different from zero, if they make a repair instead of borrowing, two different errors may arise: Diff $0-\mathrm{N}=\mathrm{N}$ and Diff $0-\mathrm{N}=0$, which occur because the student does not know how to borrow from zero. As such, a single impasse would generate two errors. Repair theory predicts that these errors will belong to the same family, since they come from the same dead end. A total of 77 different errors were categorised [46], later increasing to 121 [16], with a remaining approximately $10 \%$ that could not be diagnosed.

Learning basic maths operations, mainly addition and subtraction, has essentially been included among the aims of a large proportion of different kinds of mathematical education research over the years, involving researchers from a wide range of countries and contexts (for more detail, see [47,48]). Some of these studies focused on subtraction, and mainly on the errors and types of error committed by primary-level students when applying the algorithm (see [49-52]).

In this context, Cox [53] analysed the errors made by 744 elementary-level students in implementing the subtraction algorithm. Thirteen per cent committed errors, and $23 \%$ of students were still committing the same errors one year later. In a study by Bennett [54], involving 33 10-year-old students who 
completed a total of 1549 subtractions, 22.2\% were incorrectly performed. Brown and Burton [33] collected data from 1325 students in the fourth, fifth and sixth grades in Nicaragua. The results from 19,500 completed subtractions showed that almost $40 \%$ of students committed errors, with the percentage increasing from fourth to sixth grade. Additionally, research by Young and O'Shea [41] examined 1500 subtractions performed by students aged under 10 years, of which two thirds contained errors. Studies by Cebulski and Bucher [55], VanLehn [16] and Sander [56] reported similar findings. The results of a study by López and Sánchez [51], with 357 primary-level Spanish students performing the subtractions used in a questionnaire administered by VanLehn [16], concluded that $26.61 \%$ of students correctly answered the questionnaire, $23.47 \%$ of subtractions saw errors committed and the systematic nature of the errors persisted over time. It was reported in all cases that the highest number of errors occurred with subtractions that included a zero and due to failure to understand the place value of figures in the base-ten system.

In another study, Fiori and Zuccheri [57] analysed the errors committed by 732 students aged from 9 to 12 years in Italy, using a questionnaire containing 19 subtractions that had been previously used in Brazil, to assess whether the errors committed might be related to cultural factors, teaching methods or the type of algorithm used. The results did not show significant differences, and although there was recognition of the importance of the learning methodology used, it did not always have a decisive influence on results, albeit in different cultural contexts. Fiori and Zuccheri [57] also noted that $16 \%$ of students performed subtractions in which they obtained a solution with a higher number than the top, reflecting an absence of number sense and critical thinking among students.

In short, despite having certain knowledge of studies that analysed the errors committed by primary-level students when using the subtraction algorithm, and though there are works which compared mental arithmetic in children and adults (e.g., [58]) as well as others which have compared subtraction strategies among younger and older adults (e.g., [59]), no studies have been found involving adults or university students that analyse the errors they commit when making subtractions, and no studies have been found that consider subtraction as something more than an algorithmic process.

\section{Materials and Methods}

\subsection{Sample}

A convenience sample was taken $[60,61]$ of university students from the University of Salamanca, Spain, taken from different contexts. Specifically, students were selected from three centres and three different undergraduate years in: primary teaching diploma (teaching), business sciences and small and mid-size enterprise management (business) and statistics (statistics). In total, there were 535 students aged from 18 to 47 years (Table 1). Of those students, 147 (27.5\%) were male, 303 (56.6\%) were female, and $85(15.9 \%)$ did not answer. In terms of studies completed prior to arriving at the university, 112 students had studied sciences and technology (20.9\%), 285 had studied humanities and social sciences (53.3\%) and 138 had studied other subjects (25.8\%).

Table 1. Sample of students who completed the tests, in numbers and percentages, organised by year.

\begin{tabular}{lrrrr}
\hline Centre & \multicolumn{1}{c}{ First } & \multicolumn{1}{c}{ Second } & \multicolumn{1}{c}{ Third } & \multicolumn{1}{c}{ Total } \\
\hline Teaching & $185(46.1 \%)$ & $143(35.7 \%)$ & $73(18.2 \%)$ & $401(100 \%)$ \\
Business & $64(56.6 \%)$ & $0(0.0 \%)$ & $49(43.4 \%)$ & $113(100 \%)$ \\
Statistics & $7(33.3 \%)$ & $10(47.6 \%)$ & $4(19.0 \%)$ & $21(100 \%)$ \\
\hline Total & $256(47.9 \%)$ & $153(28.6 \%)$ & $126(23.6 \%)$ & $535(100 \%)$ \\
\hline
\end{tabular}

\subsection{Instrument}

A questionnaire (Figure 1) was used containing 20 subtractions, of which 17 required borrowing (validated by VanLehn [16]). The students completed the questionnaire on an anonymous basis and also included details regarding sex (male/female/no response), age (in the following age intervals: 
18-19/20-21/22-23/24-25/over 25 years), centre (teaching/business/statistics), year (1st/2nd/3rd), studies prior to arriving at the university (science and technology/humanities and social sciences/others) and time taken to complete the questionnaire (in minutes).

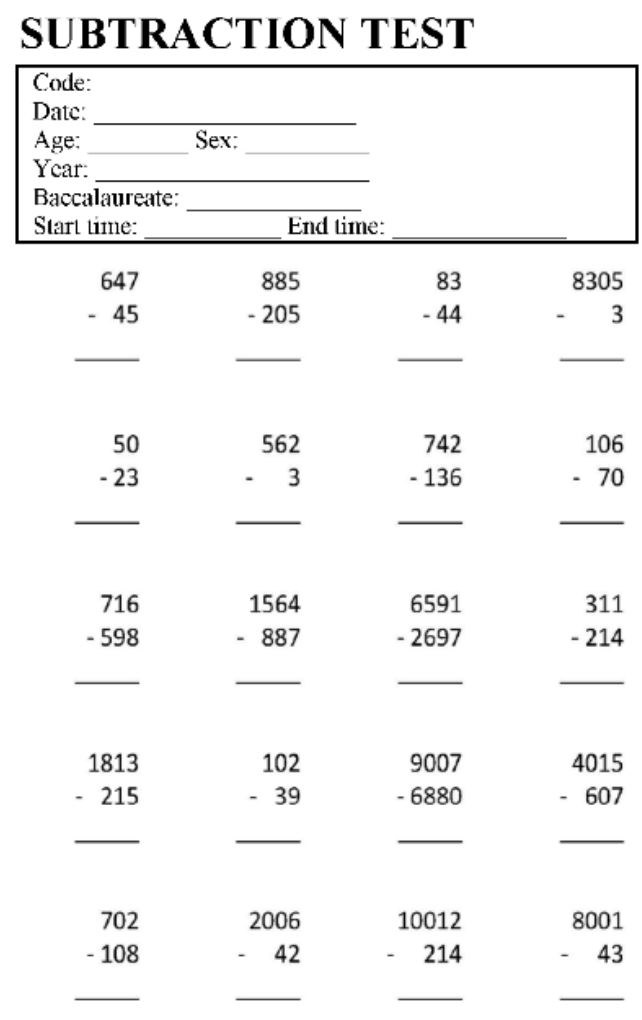

Figure 1. Questionnaire (adapted from VanLehn [16] (p. 170)).

\subsection{Preliminary Exploratory Test}

Before collecting the data, an exploratory test was carried out with 34 university students on the teaching diploma course. Data analysis showed a high percentage of errors. These data were not taken into account in this study.

\subsection{Procedure}

The students independently and anonymously answered the 20-subtraction questionnaire, in their normal classroom and in the presence of their normal professor and one of the authors of this article, in order to check that the data were collected in an adequate way. There was no time limit, although the time spent completing the questionnaire was recorded in each case. It was estimated that the questionnaire would take between 2 and $5 \mathrm{~min}$, and $10 \mathrm{~min}$ at most. All students consented to the data they provided being taken into account for this research.

\subsection{Data}

The data were the students' responses to the questionnaire. There were a total of 535 questionnaires and 10,700 subtractions.

\subsection{Analysis System}

First, each student's right and wrong answers were analysed after they had completed the questionnaire. The results were included in tables as absolute values and percentages, initially taking into account the number of errors made and subsequently organised by sex, age, centre, course, previous studies and time spent to complete the questionnaires, with comparisons performed to discover whether 
there were significant differences (Levene's test, one-way ANOVA, Student's t-test, Tamhane's T2-test). The second analysis examined the type of error committed in the erroneous subtractions, in line with the categorisation established by VanLehn [16] (See Table 2).

Table 2. Description of types of subtraction errors observed in this study (adapted from VanLehn [16] (pp. 219-230)).

\begin{tabular}{|c|c|c|}
\hline Error & Name & Description \\
\hline E4 & $0-\mathrm{N}=\mathrm{N}$ Except After Borrow & $\begin{array}{l}\text { The student thinks that } 0-\mathrm{N} \text { is } \mathrm{N} \text { except when the } \\
\text { column has been borrowed from. }\end{array}$ \\
\hline E5 & $1-1=0$ After Borrow & $\begin{array}{l}\text { If a column starts with } 1 \text { in both top and bottom and } \\
\text { is borrowed from, the student writes } 0 \text { as the answer } \\
\text { to that column. }\end{array}$ \\
\hline E6 & $1-1=1$ After Borrow & $\begin{array}{l}\text { If a column starts with } 1 \text { at the top and bottom and is } \\
\text { borrowed from, the student writes } 1 \text { as the answer to } \\
\text { that column. }\end{array}$ \\
\hline E7 & Add Borrow Decrement & $\begin{array}{l}\text { Instead of decrementing, the student adds } 1 \text {, carrying } \\
\text { to the next column if necessary. }\end{array}$ \\
\hline E8 & $\begin{array}{l}\text { Add Borrow Decrement } \\
\text { without Carry }\end{array}$ & $\begin{array}{l}\text { Instead of decrementing, the student adds one. If this } \\
\text { addition results in ten, the student does not carry but } \\
\text { simply writes both digits in the same space. }\end{array}$ \\
\hline E9 & Add Instead of Sub & The student adds instead of subtracts. \\
\hline E12 & Always Borrow & $\begin{array}{l}\text { The student borrows in every column regardless of } \\
\text { whether it is necessary. }\end{array}$ \\
\hline E19 & $\begin{array}{l}\text { Borrow across Top Smaller } \\
\text { Decrementing To }\end{array}$ & $\begin{array}{l}\text { When decrementing a column in which the top is } \\
\text { smaller than the bottom, the student adds } 10 \text { to the } \\
\text { top digit, decrements the column being borrowed } \\
\text { into and borrows from the next column to the left. } \\
\text { Further, the student skips any column that has a zero } \\
\text { over a zero or blank in the borrowing process. }\end{array}$ \\
\hline E20 & Borrow across Zero & $\begin{array}{l}\text { When borrowing across a zero, the student skips over } \\
\text { the zero to borrow from the next column. If this } \\
\text { requires them to borrow twice, they decrement the } \\
\text { same number both times. }\end{array}$ \\
\hline E22 & Borrow across Zero over Zero & $\begin{array}{l}\text { Instead of borrowing across a zero that is over a zero, } \\
\text { the student does not change the zero but decrements } \\
\text { the next column to the left instead. }\end{array}$ \\
\hline E28 & Borrow from All Zero & $\begin{array}{l}\text { When borrowing across one or more zeros, the } \\
\text { student changes all the zeros to nines, but does not } \\
\text { decrement the appropriate nonzero digit. }\end{array}$ \\
\hline E29 & Borrow from Bottom & $\begin{array}{l}\text { The student borrows from the bottom instead of } \\
\text { top row. }\end{array}$ \\
\hline E32 & Borrow from One Is Nine & $\begin{array}{l}\text { When borrowing from a } 1 \text {, the student changes it to } 9 \\
\text { instead of zero. }\end{array}$ \\
\hline E33 & Borrow from One Is Ten & $\begin{array}{l}\text { When borrowing from a } 1 \text {, the student changes it to } \\
10 \text { instead of zero. }\end{array}$ \\
\hline E34 & Borrow from Zero & $\begin{array}{l}\text { Instead of borrowing across a zero, the student } \\
\text { changes the zero to } 9 \text { but does not continue } \\
\text { borrowing from the column to the left. }\end{array}$ \\
\hline
\end{tabular}


Table 2. Cont

\begin{tabular}{|c|c|c|}
\hline Error & Name & Description \\
\hline E36 & Borrow from Zero Is Ten & $\begin{array}{l}\text { When borrowing across a zero, the student changes } \\
\text { the zero to } 10 \text { but does not decrement any digit to the } \\
\text { left. }\end{array}$ \\
\hline E38 & Borrow into One $=$ Ten & $\begin{array}{l}\text { When a borrow is caused by a column of the form } 1- \\
N \text {, the student changes the } 1 \text { to } 10 \text { instead of adding } \\
10 \text { to it. }\end{array}$ \\
\hline E39 & Borrow No Decrement & $\begin{array}{l}\text { When borrowing, the student correctly adds } 10 \text { but } \\
\text { does not decrement any column to the left. }\end{array}$ \\
\hline E40 & Borrow No Decrement Except Last & $\begin{array}{l}\text { The student omits decrementing unless the column } \\
\text { to be decremented is the leftmost column in the } \\
\text { subtraction. }\end{array}$ \\
\hline E44 & Borrow Only Once & $\begin{array}{l}\text { The student does the first borrow correctly in a } \\
\text { problem. They subsequently only add } 10 \text { and omit } \\
\text { the decrement. }\end{array}$ \\
\hline E45 & Borrow Skip Equal & $\begin{array}{l}\text { When decrementing, the student skips over columns } \\
\text { where the top and bottom digits are the same. }\end{array}$ \\
\hline E47 & Borrow Treat One as Zero & $\begin{array}{l}\text { When borrowing from a } 1 \text {, the student treats the } 1 \text { as } \\
\text { if it were a } 0 . \text { In other words, they change the } 1 \text { to } 9 \\
\text { and decrement the number to the left of the } 1 .\end{array}$ \\
\hline E51 & Borrowed from Don't Borrow & $\begin{array}{l}\text { When there are two consecutive borrows, the student } \\
\text { performs the first correctly but does not decrement } \\
\text { with the second (although they add } 10 \text { correctly). }\end{array}$ \\
\hline E56 & Decrement by One Plus Zeros & $\begin{array}{l}\text { When there is a borrow across one or more zeros, the } \\
\text { student decrements the number to the left of the } \\
\text { zero(s) by an extra } 1 \text { for each zero borrowed across. }\end{array}$ \\
\hline E61 & Decrement on First Borrow & $\begin{array}{l}\text { The first column that requires a borrow is } \\
\text { decremented before the column subtract is done. }\end{array}$ \\
\hline E65 & $\operatorname{Diff} 0-N=N$ & $\begin{array}{l}\text { In columns of the form } 0-\mathrm{N} \text {, the student does not } \\
\text { borrow but instead writes } \mathrm{N} \text { as the answer. }\end{array}$ \\
\hline E69 & Diff $N-N=N$ & $\begin{array}{l}\text { Whenever there is a column with the same number } \\
\text { on the top and bottom, the student writes that } \\
\text { number as the answer. }\end{array}$ \\
\hline E75 & Don't Decrement Zero over Blank & $\begin{array}{l}\text { The student does not borrow from a zero that is over } \\
\text { a blank. }\end{array}$ \\
\hline E76 & Don't Decrement Zero over Zero & $\begin{array}{l}\text { The student does not borrow from a zero that is over } \\
\text { a zero. }\end{array}$ \\
\hline E77 & $\begin{array}{l}\text { Don't Decrement Zero Until } \\
\text { Bottom Blank }\end{array}$ & $\begin{array}{l}\text { When borrowing across a zero, the student changes } \\
\text { the zero to } 10 \text { instead of } 9 \text {, unless the zero is over a } \\
\text { blank, in which case they borrow correctly. }\end{array}$ \\
\hline E79 & Double Decrement One & $\begin{array}{l}\text { When borrowing from a one, the student treats the } \\
\text { one as a zero (that is, they change the one to nine and } \\
\text { continue borrowing to the left) unless the one is over } \\
\text { a blank, in which case they do the correct thing. }\end{array}$ \\
\hline E80 & Forget Borrow over Blanks & $\begin{array}{l}\text { The student does not decrement a number that is } \\
\text { over a blank. }\end{array}$ \\
\hline E81 & Ignore Leftmost One over Blank & $\begin{array}{l}\text { When the leftmost column has a } 1 \text { over a blank, the } \\
\text { student ignores that column. }\end{array}$ \\
\hline E85 & $N-9=N-1$ After Borrow & $\begin{array}{l}\text { If a column is of the form } \mathrm{N}-9 \text { and has been } \\
\text { borrowed from, when the student does that column, } \\
\text { he subtracts one instead of nine. }\end{array}$ \\
\hline E86 & $\begin{array}{l}\mathrm{N}-\mathrm{N} \text { After Borrow Causes } \\
\text { Borrow }\end{array}$ & $\begin{array}{l}\text { The student borrows with columns of the form } \\
\mathrm{N}-\mathrm{N} \text { (after having borrowed). }\end{array}$ \\
\hline
\end{tabular}


Table 2. Cont.

\begin{tabular}{|c|c|c|}
\hline Error & Name & Description \\
\hline E88 & $\mathrm{N}-\mathrm{N}=1$ After Borrow & $\begin{array}{l}\text { If a column had the form } \mathrm{N}-\mathrm{N} \text { and was } \\
\text { borrowed from, the student writes one as the answer } \\
\text { to that column. }\end{array}$ \\
\hline E89 & $\mathrm{N}-\mathrm{N}=9$ Plus Decrement & $\begin{array}{l}\text { When a column has the same number in the top and } \\
\text { bottom, the student writes } 9 \text { as the answer and } \\
\text { decrements the next column to the left, even when no } \\
\text { borrowing is required. }\end{array}$ \\
\hline E90 & Once Borrow Always Borrow & $\begin{array}{l}\text { Once a student has borrowed, they continue } \\
\text { borrowing in every column. }\end{array}$ \\
\hline E94 & Smaller from Larger & $\begin{array}{l}\text { The student does not borrow, but in each column } \\
\text { subtracts the smaller digit from the larger one. }\end{array}$ \\
\hline E95 & Smaller from Larger Except Last & $\begin{array}{l}\text { The student answers all columns by taking the } \\
\text { smaller digit from the larger one unless the column is } \\
\text { second to the last, in which case the student borrows } \\
\text { if necessary. }\end{array}$ \\
\hline E100 & Smaller from Larger With Borrow & $\begin{array}{l}\text { When borrowing is required, the student correctly } \\
\text { decrements but subtracts the smaller digit from the } \\
\text { larger one. }\end{array}$ \\
\hline E109 & $\begin{array}{l}\text { Top Instead of Borrow From } \\
\text { Double Zero }\end{array}$ & $\begin{array}{l}\text { If a column requires borrowing from multiple zeros, } \\
\text { the student writes the top digit as the answer to that } \\
\text { column. }\end{array}$ \\
\hline E115 & Treat Top Zero as Ten & $\begin{array}{l}\text { In a } 0-\mathrm{N} \text { column, the student does not borrow, but } \\
\text { rather treats the } 0 \text { as if it were a } 9 .\end{array}$ \\
\hline E122 & Calculation & Number fact errors, such as $8-3=6$. \\
\hline E123 & Not diagnosable & \\
\hline $\mathrm{E} 301^{\mathrm{a}}$ & Decrement By 2 in Second Borrow & $\begin{array}{l}\text { When two consecutive borrows are required, the } \\
\text { student performs the first correctly but introduces a } \\
\text { two-unit decrement in the second. }\end{array}$ \\
\hline $\mathrm{E} 302^{\mathrm{a}}$ & $\begin{array}{l}\text { Units Column: } \\
\text { If } \mathrm{T}<\mathrm{B} \text {, Add Not Subtract and } \\
\text { Decrement }\end{array}$ & $\begin{array}{l}\text { When } \mathrm{T}<\mathrm{B} \text { in the units column, the student adds } \\
\text { instead of subtracting and introduces a decrement of } \\
\text { one unit in the next column. }\end{array}$ \\
\hline $\mathrm{E} 303^{\mathrm{a}}$ & $\begin{array}{l}\text { Units Column: } \\
\text { If } \mathrm{T}<\mathrm{B} \text {, Add Not Subtract and No } \\
\text { Decrement With Borrow }\end{array}$ & $\begin{array}{l}\text { When } \mathrm{T}<\mathrm{B} \text { in the units column, the student adds } \\
\text { instead of subtracting and does not introduce a } \\
\text { decrement of one unit in the next column. }\end{array}$ \\
\hline $\mathrm{E} 304^{\mathrm{a}}$ & $\begin{array}{l}\text { Units Column: } \\
\text { If } \mathrm{T}<\mathrm{B} \text {, Increase Units By } 1 \text { and } \\
\text { Decrement Borrow }\end{array}$ & $\begin{array}{l}\text { When } \mathrm{T}<\mathrm{B} \text { in the units column, the student } \\
\text { increases the result by one and decrements the } \\
\text { borrow in the next column. }\end{array}$ \\
\hline $\mathrm{E} 305^{\mathrm{a}}$ & $\begin{array}{l}\text { Units Column: } \\
\text { If } \mathrm{T}<\mathrm{B} \text {, Write Bottom }\end{array}$ & $\begin{array}{l}\text { When } \mathrm{T}<\mathrm{B} \text { in the units column, the student writes } \\
\text { the bottom digit as the result. }\end{array}$ \\
\hline $\mathrm{E} 306^{\mathrm{a}}$ & $\mathrm{N}-0=\mathrm{N}$ and Decrement & $\begin{array}{l}\mathrm{N}-0=\mathrm{N} \text { and the student introduces a decrement of } \\
\text { one unit in the next column. }\end{array}$ \\
\hline $\mathrm{E} 307^{\mathrm{a}}$ & $\mathrm{N}-0=0-\mathrm{N}$ and Decrement & $\begin{array}{l}\mathrm{N}-0=0-\mathrm{N} \text { and the student introduces a decrement } \\
\text { of one unit in the next column. If it is another } \\
\text { number instead of a zero, the student subtracts the } \\
\text { bottom from the top and decrements the borrow. }\end{array}$ \\
\hline $\mathrm{E} 308^{\mathrm{a}}$ & $\mathrm{E} 40+\mathrm{E} 69$ & $\begin{array}{l}\text { Combination of errors } 40 \text { and } 69 \text { from VanLehn's } \\
\text { glossary of errors. }\end{array}$ \\
\hline
\end{tabular}

${ }^{a}$ New errors generated in this research.

An example of the analysis is as follows:

Analysis example (Figure 2):

The analysis example shows that subtractions S5, S7, S9, S10, S11, S12, S13, S14, S15, S16, S17, S18, S19 and S20, numbered from left to right and from top to bottom, have a Smaller-From-Larger error type, involving subtracting the smaller number from the larger one in each column. For example, the student solves subtraction S11 as follows: $6591-2697=4106$ (that is, $7-1=6,9-9=0,6-5=1$ 
and $6-2=4$ ). The student solves subtraction S15 as follows: $9007-6880=3223$, where in addition to the Smaller-From-Larger error, the Treat-Top-Zero-As-Ten error is also present, consisting of treating the 0 at the top as a 10 (that is, $10-7=3,10-8=2,10-8=2$ and $9-6=3$ ). Additionally, in subtractions S14, S16, S19 and S20, the student also commits the Smaller-From-Larger error. In subtraction S14, they calculate $102-39=77(9-2=7$ and $10-3=7)$; they solve subtraction S16 as $4015-607=3412$ (that is, $7-5=2,1-0=1$ and $40-6=34$ ); and in subtraction S19, the student calculates 10,012 - 214 $=9802$ (that is, $4-2=2,1-1=0$ and $100-2=98$ ).

\begin{tabular}{|c|c|c|c|}
\hline \multicolumn{4}{|c|}{ SUBTRACTION TEST } \\
\hline \multicolumn{4}{|c|}{ 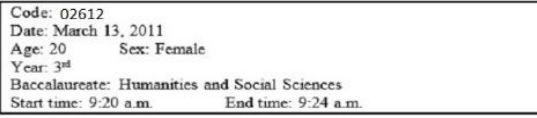 } \\
\hline 647 & 885 & 83 & 8305 \\
\hline-45 & -205 & -44 & \\
\hline 602 & 680 & 39 & 8302 \\
\hline 50 & 562 & 742 & 106 \\
\hline-23 & - 3 & -136 & -70 \\
\hline 33 & 559 & 614 & 36 \\
\hline 716 & 1564 & 6591 & 311 \\
\hline-598 & -887 & -2697 & -214 \\
\hline 282 & 1323 & 4106 & 103 \\
\hline 1813 & 102 & 9007 & 4015 \\
\hline-215 & -39 & -6880 & -607 \\
\hline 1602 & 77 & 3223 & 3412 \\
\hline 702 & 2006 & 10012 & 8001 \\
\hline-108 & -42 & -214 & - 43 \\
\hline 606 & 2044 & 9802 & 7062 \\
\hline
\end{tabular}

Figure 2. Questionnaire completed by a student including Smaller-From-Larger errors.

For some subtractions, results even higher than the value of the top row are obtained (Figure 2: S18 2044 > 2006), which might indicate an absence of critical thinking on the part of these students and a need to include strategies to strengthen this aspect in the learning process for subtraction, and for basic maths in general.

\section{Results}

This section contains the results of the analysis of student responses, carried out when they had completed the 20-subtraction questionnaire.

\subsection{Errors Commited by University Students}

The errors committed by the 535 students in completing the 20 subtractions are set out below (Table 3).

Table 3. Number of errors committed by students when completing the questionnaire, based on centre.

\begin{tabular}{ccccc}
\hline Total Errors & Teaching & Statistics & Business & Total \\
\hline 0 & $109(27.2 \%)$ & $2(9.5 \%)$ & $18(15.9 \%)$ & $129(24.1 \%)$ \\
1 & $85(21.2 \%)$ & $8(38.1 \%)$ & $27(23.9 \%)$ & $120(22.4 \%)$ \\
2 & $74(18.5 \%)$ & $2(9.5 \%)$ & $21(18.6 \%)$ & $97(18.1 \%)$ \\
3 & $58(14.5 \%)$ & $4(19.0 \%)$ & $12(10.6 \%)$ & $74(13.8 \%)$ \\
4 & $31(7.7 \%)$ & $2(9.5 \%)$ & $10(8.8 \%)$ & $43(8.0 \%)$ \\
5 or more & $44(10.9 \%)$ & $3(14.4 \%)$ & $25(22.2 \%)$ & $72(13.6 \%)$ \\
\hline Total & $401(100 \%)$ & $21(100 \%)$ & $113(100 \%)$ & $535(100 \%)$ \\
\hline
\end{tabular}


Only $24.1 \%$ of the students correctly answered all 20 subtractions, meaning that $75.9 \%$ made at least one error. Combining the students who correctly completed the entire questionnaire with those who made a single error produces a percentage of $46.54 \%$, meaning that over half of the students gave wrong answers for at least two of the 20 subtractions.

There were no significant differences in these results based on: age; year, although in the third year there was an increase in correct questionnaires that might be due to future primary teachers having just completed their work placements at primary education centres and, very probably, having had to deal with the execution of algorithms; and studies prior to arriving at the university. There were significant differences based on: sex, insofar as the men committed more errors compared to the women (Student's $t$-test: $\mathrm{t}(448)=1.98, * p=0.04)$ ), in addition, the percentage of women who did not commit any errors was higher than the percentage of men $(27.1 \%>19.0 \%)$ and a higher percentage of men than women fell into the category of having committed five errors or more; centre, insofar as the teaching diploma students committed fewer errors compared to the business and statistics students (Student's $t$-test: $\left.\mathrm{t}(533)=-2.518,{ }^{*} p=0.012\right)$; and time taken to complete the questionnaire, with a difference between students who took fewer than five minutes and those who took more than five minutes (Tamhane's T2-test: $>5$ vs. $(0,2],{ }^{*} p=0.000 ;>5$ vs. $(2,3],{ }^{*} p=0.000 ;>5$ vs. $(3,4], * p=0.000$ y $>5$ vs. $\left.(4,5],{ }^{*} p=0.004\right)$.

\subsection{Type of Error Committed by University Students in the Erroneous Subtractions}

Second, when analysing the type of error made in erroneous subtractions, the subtractions that students most frequently got wrong were initially considered. The students made errors in 1258 of the 10,700 subtractions, representing $11.76 \%$ of the total. These errors were distributed by subtraction as shown below (the subtractions in the questionnaire were numbered from left to right and from top to bottom; Table 4).

Table 4. Number of errors made by students for each of the 20 subtractions in the questionnaire.

\begin{tabular}{ccc}
\hline Subtraction & Number of Errors & Percentage of Questionnaires \\
\hline S13 & 128 & $23.9 \%$ \\
S11 & 107 & $20.0 \%$ \\
S9 & 94 & $17.6 \%$ \\
S19 & 91 & $17.0 \%$ \\
S20 & 88 & $16.4 \%$ \\
S10 & 85 & $15.9 \%$ \\
S15 & 82 & $15.3 \%$ \\
S18 & 80 & $15.0 \%$ \\
S16 & 76 & $14.2 \%$ \\
S17 & 70 & $13.1 \%$ \\
S14 & 53 & $9.9 \%$ \\
S5 & 52 & $9.7 \%$ \\
S12 & 47 & $8.8 \%$ \\
S3 & 41 & $7.7 \%$ \\
S1 & 40 & $7.5 \%$ \\
S7 & 39 & $7.3 \%$ \\
S6 & 31 & $5.8 \%$ \\
S8 & 26 & $4.9 \%$ \\
S2 & 20 & $3.7 \%$ \\
S4 & 8 & $1.5 \%$ \\
\hline
\end{tabular}

Total erroneous subtractions: 1258

${ }^{1}$ For example, subtraction 13 was incorrectly answered by 128 students out of the 535 who completed the questionnaire, representing $23.9 \%$ of students.

The ten subtractions that generated the highest number of errors reveal various issues. One cause that may have influenced student error is the structure of the subtractions in the questionnaire. The 17 subtractions that involved borrowing included the top 10 in terms of error rate. In addition 
to this, the subtractions S13, S11, S19 and S17 could be described as containing a column where the top and bottom include the same number ( 1 in some cases and 9 and 0 in others); in subtractions S19, S20, S15 and S18, there are various consecutive zeros on the top, and in subtractions S13, S19 and S10, there is a 1 on the top and a blank on the bottom, although the 1 is only affected by borrowing in S10. Subtraction S9 does not fit any of these structures, but as with some of the others, it involves the numbers 1 and 9 ( 1 over 9). Examining these structural peculiarities in more detail below, the 10 subtractions are organised in a chart that shows the relationship between the top and the bottom for all of them $(\mathrm{T}=$ Top, $\mathrm{B}=$ Bottom, $\mathrm{S}=$ Subtraction, Figure 3$)$.

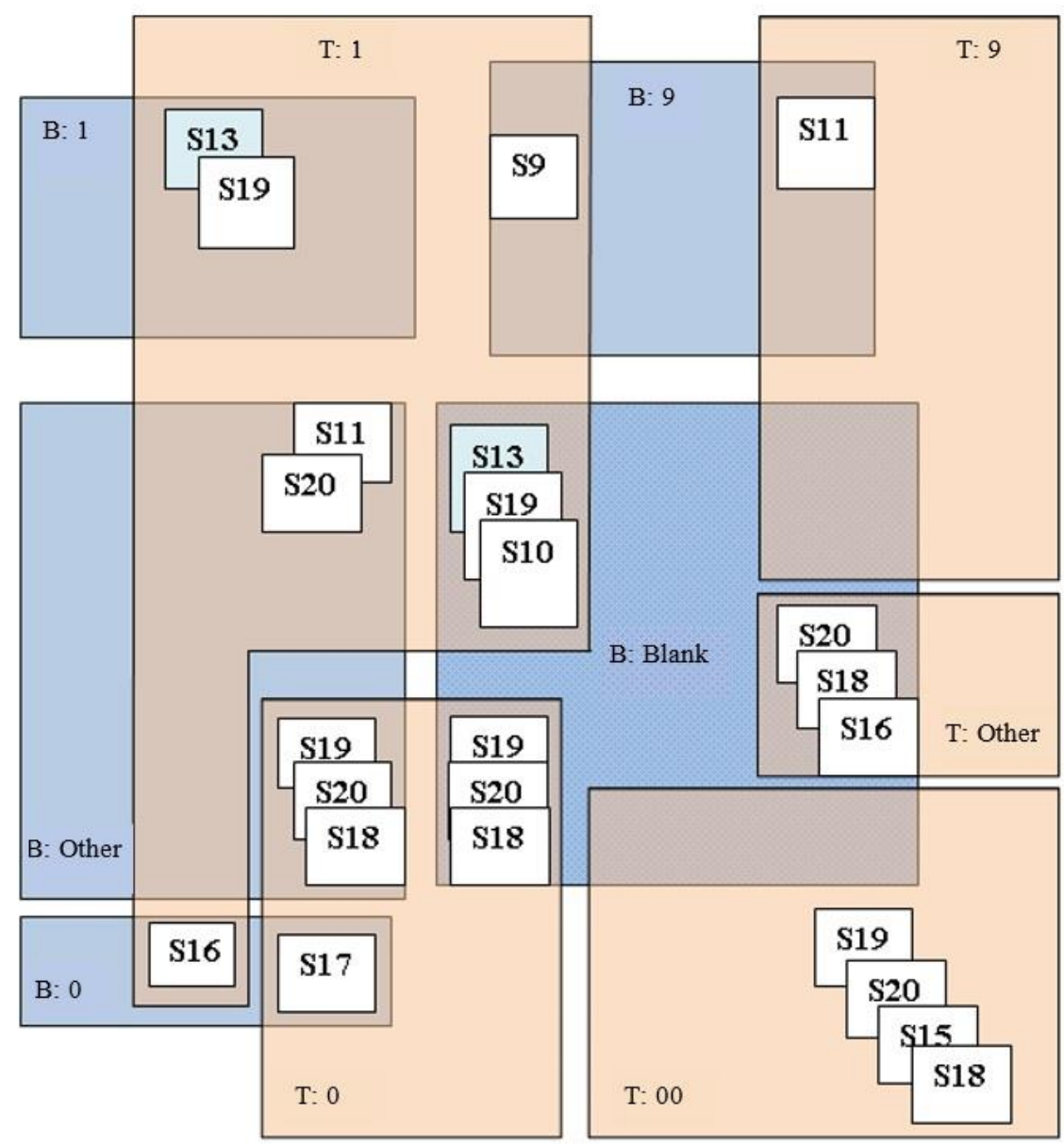

Figure 3. Organisation of the 10 subtractions with the highest error rate based on their structure, according to numbers included on the top and bottom. Note: T: 1, 9, 0, 00 and other, mean that the top of the subtraction contains, in each case, 1, 9, 0, 00 or a value other than the foregoing. B: 1, 9, 0, blank and other, mean that the bottom of the subtraction contains, in each case, 1, 9, 0, blank or a value other than the foregoing. SX, subtraction number X. For example, subtraction $13(\mathrm{~S} 13,1813-215)$ could be described as containing a column where the top and bottom include a $1(T=1, B=1)$, and as containing a 1 on the top over a blank on the bottom $(\mathrm{T}=1, \mathrm{~B}=$ Blank).

Figure 3 shows that, in terms of the bottom, the subtractions with the highest error rate had a structure in which the bottom had fewer digits than the top (six of them). With regard to the top, the subtractions with the highest error rate had a structure that included a 1 in the top (seven of them).

Taking into account the error types that occurred in each of the 10 subtractions with the highest error rate produces the below table (only showing the seven highest-frequency errors, Table 5). 
Table 5. Types of errors committed in the 10 subtractions with the highest error rate (only showing the seven highest-frequency errors in each case).

\begin{tabular}{|c|c|c|c|c|}
\hline $\begin{array}{l}\text { Subtraction } \\
\text { Number }\end{array}$ & $\begin{array}{l}\text { Total Errors } \\
\quad(\%)\end{array}$ & $\begin{array}{l}\text { Most Frequent } \\
\text { Error Types }\end{array}$ & $\begin{array}{l}\text { Example of Error in } \\
\text { Each Subtraction }\end{array}$ & $\begin{array}{l}\text { Number of Errors } \\
\text { of Each Type }\end{array}$ \\
\hline \multirow{7}{*}{$\begin{array}{l}\text { Subtraction 13: } \\
1813-215=1598\end{array}$} & \multirow{7}{*}{$128(23.9 \%)$} & E81 & $\begin{array}{l}1813-215=598^{a} \\
1813-215=608\end{array}$ & $56(25.11 \%)$ \\
\hline & & E12 & $1813-215=598$ & $50(22.42 \%)$ \\
\hline & & E5 & $1813-215=1608$ & $22(9.83 \%)$ \\
\hline & & E122 & $1813-215=1597$ & $12(5.38 \%)$ \\
\hline & & E19 & $1813-215=1607$ & $11(4.93 \%)$ \\
\hline & & E6 & $1813-215=1618$ & $10(4.48 \%)$ \\
\hline & & E33 & $1813-215=1698$ & $10(4.48 \%)$ \\
\hline \multirow{7}{*}{$\begin{array}{l}\text { Subtraction 11: } \\
6591-2697=3894\end{array}$} & \multirow{7}{*}{$107(20.0 \%)$} & E40 & $6591-2697=3904$ & $37(15.16 \%)$ \\
\hline & & E69 & $6591-2697=3994$ & $33(13.52 \%)$ \\
\hline & & E122 & $6591-2697=3899$ & $28(11.47 \%)$ \\
\hline & & E45 & $6591-2697=3804$ & $13(5.33 \%)$ \\
\hline & & E89 & $6591-2697=3894$ & $10(4.1 \%)$ \\
\hline & & E301 & $6591-2697=3794$ & $10(4.1 \%)$ \\
\hline & & E7 & $6591-2697=4014$ & $8(3.28 \%)$ \\
\hline \multirow{7}{*}{$\begin{array}{l}\text { Subtraction 9: } \\
716-598=118\end{array}$} & \multirow{7}{*}{$\begin{array}{c}94 \\
(17.6 \%)\end{array}$} & E33 & $716-598=218$ & $40(30.1 \%)$ \\
\hline & & E122 & $716-598=116$ & $22(16.54 \%)$ \\
\hline & & E302 & $716-598=114$ & $8(6.01 \%)$ \\
\hline & & E19 & $716-598=117$ & $5(3.76 \%)$ \\
\hline & & E32 & $716-598=208$ & $4(3.01 \%)$ \\
\hline & & E40 & $716-598=128$ & $4(3.01 \%)$ \\
\hline & & E47 & $716-598=108$ & $4(3.01 \%)$ \\
\hline \multirow{7}{*}{$\begin{array}{l}\text { Subtraction 19: } \\
10012-214=9798\end{array}$} & \multirow{7}{*}{$\begin{array}{c}91 \\
(17.0 \%)\end{array}$} & E5 & $10012-214=9808$ & $14(7.33 \%)$ \\
\hline & & E80 & $10,012-214=10,798$ & $14(7.33 \%)$ \\
\hline & & E34 & $10,012-214=19,798$ & $11(5.76 \%)$ \\
\hline & & E75 & $10,012-214=10,798$ & $11(5.76 \%)$ \\
\hline & & E33 & $10,012-214=9898$ & $10(5.24 \%)$ \\
\hline & & E28 & $10,012-214=19,798$ & $9(4.71 \%)$ \\
\hline & & E122 & $10,012-214=9998$ & $9(4.71 \%)$ \\
\hline \multirow{7}{*}{$\begin{array}{l}\text { Subtraction 20: } \\
8001-43=7958\end{array}$} & \multirow{7}{*}{$\begin{array}{c}88 \\
(16.4 \%)\end{array}$} & E77 & $8001-43=7968$ & $13(8.67 \%)$ \\
\hline & & E34 & $8001-43=8958$ & $12(8 \%)$ \\
\hline & & E80 & $8001-43=8058$ & $12(8 \%)$ \\
\hline & & E122 & $8001-43=7956$ & $11(7.33 \%)$ \\
\hline & & E28 & $8001-43=8958$ & $10(6.67 \%)$ \\
\hline & & E75 & $8001-43=8058$ & $10(6.67 \%)$ \\
\hline & & E38 & $8001-43=7957$ & $8(5.33 \%)$ \\
\hline \multirow{7}{*}{$\begin{array}{l}\text { Subtraction 10: } \\
1564-887=677\end{array}$} & \multirow{7}{*}{$\begin{array}{c}85 \\
(15.9 \%)\end{array}$} & E122 & $1564-887=657$ & $31(21.68 \%)$ \\
\hline & & E44 & $1564-887=777$ & $17(18.89 \%)$ \\
\hline & & E51 & $1564-887=1777$ & $13(9.09 \%)$ \\
\hline & & E9 & $1564-887=2451$ & $9(6.29 \%)$ \\
\hline & & E29 & $1564-887=897$ & $8(5.59 \%)$ \\
\hline & & E81 & $1564-887=787$ & $8(5.59 \%)$ \\
\hline & & E80 & $1564-887=1677$ & $7(4.89 \%)$ \\
\hline \multirow{7}{*}{$\begin{array}{l}\text { Subtraction 15: } \\
9007-6880=2127\end{array}$} & \multirow{7}{*}{$\begin{array}{c}82 \\
(15.3 \%)\end{array}$} & E34 & $9007-6880=3127$ & $30(19.87 \%)$ \\
\hline & & E28 & $9007-6880=3117$ & $28(18.54 \%)$ \\
\hline & & E36 & $9007-6880=3227$ & $13(8.61 \%)$ \\
\hline & & E39 & $9007-6880=3227$ & $13(8.61 \%)$ \\
\hline & & E56 & $9007-6880=1127$ & $8(5.3 \%)$ \\
\hline & & E307 & $9007-6880=2113$ & $7(4.63 \%)$ \\
\hline & & E306 & $9007-6880=2117$ & $7(4.63 \%)$ \\
\hline \multirow{7}{*}{$\begin{array}{l}\text { Subtraction 18: } \\
2006-42=1964\end{array}$} & \multirow{7}{*}{$\begin{array}{c}80 \\
(15.0 \%)\end{array}$} & E12 & $2006-42=1954$ & $33(24.81 \%)$ \\
\hline & & E56 & $2006-42=964$ & $18(13.53 \%)$ \\
\hline & & E75 & $2006-42=2064$ & $11(8.27 \%)$ \\
\hline & & E80 & $2006-42=2064$ & $10(7.52 \%)$ \\
\hline & & E115 & $2006-42=2064$ & $7(5.26 \%)$ \\
\hline & & E122 & $2006-42=1963$ & $7(5.26 \%)$ \\
\hline & & E28 & $2006-42=2964$ & $6(4.51 \%)$ \\
\hline
\end{tabular}


Table 5. Cont.

\begin{tabular}{lclcr}
\hline $\begin{array}{c}\text { Subtraction } \\
\text { Number }\end{array}$ & $\begin{array}{c}\text { Total Errors } \\
\mathbf{( \% )}\end{array}$ & $\begin{array}{c}\text { Most Frequent } \\
\text { Error Types }\end{array}$ & $\begin{array}{c}\text { Example of Error in Each } \\
\text { Subtraction }\end{array}$ & $\begin{array}{c}\text { Number of Errors } \\
\text { of Each Type }\end{array}$ \\
\hline & & E12 & $4015-607=3308$ & $19(12.5 \%)$ \\
& & E90 & $4015-607=3308$ & $16(10.53 \%)$ \\
Subtraction 16: & 76 & E86 & $4015-607=4308$ & $13(8.55 \%)$ \\
$4015-607=3408$ & $(14.2 \%)$ & E80 & $4015-607=4408$ & $12(7.89 \%)$ \\
& & E40 & $4015-607=3418$ & $11(7.24 \%)$ \\
& E65 & $4015-607=4608$ & $9(5.92 \%)$ \\
& & E115 & $4015-607=4408$ & $9(5.92 \%)$ \\
\hline & E34 & $702-108=694$ & $26(23.21 \%)$ \\
Subtraction 17: & E122 & $702-108=596$ & $10(8.93 \%)$ \\
$702-108=594$ & 70 & E28 & $702-108=694$ & $9(8.03 \%)$ \\
& $(13.1 \%)$ & E76 & $702-108=604$ & $7(6.25 \%)$ \\
& & E36 & $702-108=604$ & $6(5.36 \%)$ \\
& & E19 & $702-108=603$ & $5(4.46 \%)$ \\
Total & & $702-108=614$ & $4(3.57 \%)$ \\
\hline
\end{tabular}

Observation: in subtraction 11, errors 40 and 69 occurred together on the majority of occasions (31 times). ${ }^{\text {a }}$ Example of error. The most frequent error for subtraction 13 was E81 (Ignore Leftmost One Over Blank). It can be observed that, regardless of whether the operation is started correctly $(1813-215=598)$ or not $(1813-215=608)$, in both cases, the result is incomplete because the column leftmost, where a 1 appears over a blank, has been ignored.

Taking subtraction $13(1813-215)$ as an example to help understand Table 5, the most frequent errors for this subtraction were: E81 (56 times, Ignore Leftmost One Over Blank), E12 (50 times, Always Borrow), E5 (22 times, 1 - 1 = 0 After Borrow), E122 (12 times, Calculation), E19 (11 times, Borrow Across Top Smaller Decrementing To), E6 (10 times, 1 - 1 = 1 After Borrow) and E33 (10 times, Borrow From One Is Ten).

A comparison of these results with those for primary students shows that the two groups (university students and students in primary education) were almost identical in terms of the top 10 subtractions for which errors were committed. For example, the results reported by López and Sánchez [51] used the same questionnaire and found that the subtractions with the highest error rate among primary students, ordered from highest to lowest number of errors, were S19, S20, S18, S17, S13, S16, S10, S15, S11, S12, S14, S9, S8, S6, S5, S7, S3, S2, S4 and S1. Specifically, the 10 subtractions with the highest error rate were the same for both university and primary students, with only the order changing, in the cases of S19, S20, S18, S17, S13, S16, S10, S15 and S11, to which were added S9 for university students and S12 for primary students. In both cases, the five subtractions with the highest error rate included S13, S19 and S20. Moreover, when taking into account error rate and error type for these 10 subtractions, all of them involved errors E9, E39, E40 and E122, and seven or more of them produced errors E19, E29, E44, E61, E100 and E304.

Having analysed the error types produced by university students, we examined whether the typology of these errors was related to aspects concerning when the algorithm was learned; in other words, whether the typology of errors persists over time. This was done by comparing the results obtained in this study with the errors systematically made by primary students in completing the same questionnaire ([51]) (See Table 6).

The majority of the subtraction errors most frequently made by university students coincided with those occurring in primary education. Additionally, the findings of this study show that the errors made by university students fundamentally coincided with the errors identified as systematic in the study by López and Sánchez [51]. This is interesting because it appears to show that errors made in primary education persist over time despite the years that pass after university students have completed compulsory primary education and the multitude of occasions on which they will surely have performed subtractions for various purposes, in both their everyday and academic lives. 
Table 6. Most frequent error types committed by university students in the subtractions they completed compared to primary students.

\begin{tabular}{|c|c|c|c|c|}
\hline Error & Frequency in Our Study & $\begin{array}{l}\text { Order According to } \\
\text { Frequency in Our Study }\end{array}$ & $\begin{array}{l}\text { Order According to } \\
\text { Frequency in Primary } \\
\text { Education }^{1}\end{array}$ & Systematic Errors ${ }^{1}$ \\
\hline E122 & 212 & 1 & 1 & \\
\hline E12 & 140 & 2 & 6 & * \\
\hline E39 & 96 & 3 & 2 & * \\
\hline E34 & 94 & 4 & & * \\
\hline E40 & 91 & 5 & & * \\
\hline E80 & 78 & 6 & 18 & * \\
\hline E81 & 71 & 7 & & * \\
\hline E28 & 67 & 8 & & * \\
\hline E33 & 67 & 9 & & * \\
\hline E19 & 54 & 10 & 4 & \\
\hline E94 & 50 & 11 & 21 & * \\
\hline E115 & 50 & 12 & & \\
\hline E9 & 48 & 13 & 10 & \\
\hline E69 & 48 & 14 & & \\
\hline E5 & 47 & 15 & 3 & * \\
\hline E7 & 43 & 16 & 19 & \\
\hline E29 & 39 & 17 & & \\
\hline E44 & 37 & 18 & & * \\
\hline E56 & 34 & 19 & & \\
\hline $\mathrm{E} 302^{\mathrm{a}}$ & 34 & 20 & & \\
\hline E65 & 32 & 21 & 20 & * \\
\hline E75 & 32 & 22 & & \\
\hline E308 ${ }^{a}$ & 32 & 23 & & \\
\hline E304 a & 31 & 24 & & \\
\hline E100 & 30 & 25 & & \\
\hline E36 & 29 & 26 & 12 & * \\
\hline E4 & 27 & 27 & & \\
\hline E85 & 26 & 28 & & \\
\hline E89 & 26 & 29 & & \\
\hline E88 & 25 & 30 & & \\
\hline E123 b & 24 & 31 & & \\
\hline E61 & 21 & 32 & & \\
\hline E6 & 20 & 33 & 17 & * \\
\hline E79 & 19 & 34 & & \\
\hline E95 & 19 & 35 & & \\
\hline E77 & 18 & 36 & & \\
\hline E8 & 17 & 37 & 16 & \\
\hline E51 & 17 & 38 & & \\
\hline E20 & 15 & 39 & 5 & \\
\hline E45 & 15 & 40 & & \\
\hline E306 a & 15 & 41 & & \\
\hline E307 a & 15 & 42 & & \\
\hline E38 & 14 & 43 & & * \\
\hline E47 & 14 & 44 & & \\
\hline E301 a & 13 & 45 & & \\
\hline
\end{tabular}

${ }^{1}$ López and Sánchez [51]. * Indicates the type of errors committed by university students in this study, which corresponded to the errors systematically made by primary-level students [51]. ${ }^{a}$ Use of 301 in place of 101, and so on, to easily catalogue the new errors observed in this study. ${ }^{\mathrm{b}} \mathrm{E} 123=$ not diagnosable.

\section{Discussion}

For the results obtained in this study, analysis of the responses of 535 university students in answering 20 subtraction questions showed that only one quarter of those students $(24.11 \%)$ answered correctly. If one assumes that committing an error in respect to one calculation may be understandable, $46.54 \%$ of students made one error at most-almost half of the sample. If this assumption is extended to a maximum of two errors, $64.67 \%$ of students achieved this standard (almost two thirds). In this latter, most benevolent case of committing a maximum of two errors, one third of students did not achieve the standard. This is a fairly high figure if one considers that subtraction is one of the fundamental elements of basic maths that is learned during the first school years of compulsory education, fundamentally because it is commonly used in ordinary life. These findings are similar to those obtained for primary students. 
Referring as it does to university students, this finding is surprising and leads to various questions, including the following: do students who do not learn to use the subtraction algorithm in primary education still not fully know how to use it through further years and even when they reach university? Have there been no filters post-compulsory education that have required these students to perfect the execution of the subtraction algorithm? Finally, has the fact that they do not have in-depth understanding of the algorithm not proven to be an impediment to students successfully passing through further years? This is without forgetting, moreover, that these university students are supposedly a subgroup of primary education students who have completed the education that is compulsory for all citizens; those who attend university supposedly have higher intellectual or working capacity or more interest in continuing to perfect and specialise their education.

These findings cause us to doubt whether subtraction truly is something that is commonly used in ordinary life. If this were the case, this being basic maths, it is not comprehensible for there to be such a high number of errors. Perhaps the use of calculators means that it is no longer absolutely necessary today to perform subtraction on a habitual basis in everyday life, or at least that adults do not consider it to be truly necessary. This would require more research in various senses and might even lead to the possibility of reconsidering the teaching and learning of subtraction in compulsory education, with the implementation of different didactic methodologies. This might also be applicable to the rest of basic maths.

It is clear that any citizen uses, or should use, subtraction on an almost daily basis. Further, a calculator is not always available, or at least not always used. This circumstance should cause educators to reflect on the reasons for these results. Do citizens-not all, but many-really not commonly perform subtractions? Do they not react to the huge quantity of information that is constantly appearing in the media, or when they perform daily chores, many of which require subtraction, do they accept the results without even checking whether the information they are receiving is correct? If this were true, such a lack of critical spirit and preparedness to verify what is received becomes a matter of concern that cannot be dismissed as merely of anecdotal interest.

Other aspects are striking. It appears that teaching diploma students were the group that best completed the questionnaire, with even significant differences separating them from business and statistics students. What is the cause of these results? Could it be that the teaching students perceived the questionnaire as being relevant to their interests, in the awareness that they would have to implement this activity in their future professional work-something that would not be felt by business or statistics students? More research would be useful in this regard. Perhaps the relevance of the proposed task to their interests motivated those students to try their best, and this was not the case for the business or statistics students. Various studies have reported that when tasks are proposed in contexts that are relevant to students, better results are achieved (see [62]). This can open up paths for future research. However, in any case, was subtraction not understood to be something that any citizen must develop, and therefore relevant to all the students? Business and statistics students also have to perform subtraction as citizens, as well as in their training as university students. Does this not cause them to perceive that they will, or must, frequently perform subtraction?

What is more, a subgroup of teaching diploma students-those who had just completed their work placements at primary education centres-obtained better results than the other students on the same course. This may be due to the previous explanation that they perceived subtraction as relevant to what they were doing, which requires us to ask again: is subtraction not relevant for any citizen, university student or otherwise? Do students not commonly perform subtraction? Perhaps we are arriving at the essence of the problem: at these ages, subtraction is not commonly performed.

The structure of subtractions might have had an influence on the errors made. An examination of the subtractions in respect to which the university students made the most errors in this study shows that in addition to them all requiring borrowing, the subtractions that proved most difficult for the students to solve included a column where the top and bottom contained the same digit, 
various consecutive zeros or a one in the top, or a bottom containing fewer digits than the top. This is interesting as it might open up pathways for new educational proposals.

No research was found involving university students that could be compared with these results. However, it is possible to compare the results with subtractions for which primary students committed most errors, such as those in the study by López and Sánchez [51], which were almost the same as those in this study. A more detailed examination of the structure of those subtractions shows that the difficulty in resolving them was mainly due to them requiring borrowing (which is corroborated in the study by Cebulski and Bucher [55]), and to the difficulty of understanding the place value system and zero as a digit and a number $([51,57])$. This may have educational implications in terms of treating these aspects as fundamental to teaching and learning the subtraction algorithm. The method used to apply the subtraction algorithm may also be important (in the study published by Fiori and Zuccheri [57], students who solved subtractions using the Australian algorithm made fewer errors than those who used the traditional algorithm, although there were not significant differences). This shows that errors made when performing subtractions are similar in different contexts, which reinforces the importance of these findings not only in the Spanish context but also for the international mathematical education community.

In some of the subtractions performed by the university students, the result obtained was higher than the top row, which should catch anyone's attention whether or not they have adequate knowledge of the subtraction algorithm. It appears that this was not the case for many university students. For example, if we consider the example included in the Materials and Methods section, it does not appear acceptable to produce the answer 3223 (Figure 2) as a result for subtraction S15, 9007 - 6880. It can easily be observed from an overall check upon completion of the sum, without checking whether the algorithm has actually been correctly applied, that the sum of 6880 plus 3223 is considerably higher than 9007 . This has also been observed in the results obtained from analysing subtractions performed by primary students (see [57]).

These situations, which do not appear to be isolated, seem to reflect an absence of number sense and a lack of critical thinking among students, which may mean a lack of training in this respect; perhaps too much emphasis on learning the subtraction algorithm has caused scant critical understanding of what it means. Too much emphasis may have been placed on rote and algorithmic learning at the expense of reasoning and creativity. In terms of the subtraction algorithm learning process, the fact that these students are from different educational and training backgrounds makes the problem arguably more widespread than it might initially be supposed, meaning that attention should perhaps be focused on the compulsory education stages, where various studies such as that published by Resnick [8] have reported that many children solidly internalise the construction of conceptual meanings of numbers in the form of units without understanding the place value of digits within sums. Applied to the striking findings of this research, this circumstance means that one can at least doubt the instructive methods implemented to teach the algorithm during compulsory education. Efforts should hence be directed at developing more creative and critical and less mechanical didactic methodologies, in order to improve learning regarding this operation and what is required of it in everyday life. Subtractions may not be frequently performed in everyday life, but estimates are constantly made. These estimates can reveal a number sense that would not accept an exorbitant price for three or four simple products purchased at a butcher's, whether due to error or other causes, where even if the algorithmic operation has not been carefully performed, an approximate estimate of the expected cost should reveal a number sense that most citizens show or should show.

Specifically, when someone performs a basic calculation or resolves a problem, it is logical that upon completion they should consider whether the result obtained is in line with the proposed calculation or problem to be solved (this can be understood as the final stage of problem solving identified by Polya [63], involving a retrospective view). If this were to happen at a particular time, an adequate critical approach should lead to the conclusion that there must have been some error in the calculation, and this is what is understood as number sense (see [64]). With regard to this issue, 
authors including Cobb and Wheatley [65], Cobb, Yackel, Wood, Wheatley and Merkel [66], Fuson [47] and Kamii and Lewis [67] have emphasised that the algorithm should be taught from a comprehensive and critical viewpoint, above all stressing number sense over and above the strict teaching of the steps in the procedure. Some of the training approaches for teachers who will explain subtraction could be focused along these lines.

Perhaps this peculiarity does not only materialise when learning the subtraction algorithm; it might also extend to the learning of other basic maths and even beyond that to the development of learning in mathematics and perhaps in other subjects. This scarcity or absence of number sense among university students might even be part of a more general issue, to which reference has previously been made: their lack of critical spirit. This, which might be understood in a broad and ambitious context with the aim of training students as future citizens, could also include specific issues such as something that is considered apparently mechanical—-the execution of an algorithm—but which also requires reasoning, critical spirit and common sense.

The limitations of the study include the convenience nature of the sample, and the study would have to be extended to be able to generalise the results. However, the results remain interesting and seem logical based on what is known about the subtraction algorithm. The data were collected anonymously, which hindered subsequent follow-up regarding particularly striking individual cases, for example, through individual interviews that would have facilitated a more in-depth examination of how the subtractions were approached and, in turn, the causes of the errors that were made.

In terms of future prospects, it would be useful to carry out research analysing the errors that other university students (as, for example, art university students or political science university students) make when they perform subtraction and to investigate their understanding and use of this basic mathematical operation. A study in this sense with adults would make it possible to complete a cycle of knowledge of the errors that occur when performing the subtraction algorithm and, based on that knowledge, open up pathways for the development of actions to attempt to improve the learning of subtraction or even, if considered appropriate, to change the way in which the subtraction algorithm is learned, for example, by reducing mechanical learning of the algorithm and strengthening learning of the number sense that could facilitate a changed view of this basic maths, rendering it not merely mechanical but critical and reflective. Other possibilities as future research could be to design a new questionnaire including word problems or modelling problems on subtraction (see [68]) in order to experiment it and to compare the results obtained with those of this study.

One specific proposal that entails the preparation and implementation of didactic methodologies that promote more significant learning could be aimed at linking subtraction learning with contexts that are more relevant to the everyday life in which the calculation is used, and not always in an algorithmic form. More specifically, for example, primary students could be shown correct or incorrect subtractions, such as those completed by the university students in this study, in order for the primary students to identify which are erroneous and why the error occurred. Based on the students' work and perceptions, potentially carried out and discussed as a group, the teacher can analyse the types of error arising together with the students, which could indirectly impact on the algorithm required for the subtraction and on how to perform the subtraction adequately. This working approach might be expected to help understand the causes of subtraction errors as the primary students perform subtractions. It would be useful for this proposed work to be adequately planned.

\section{Conclusions}

This study analysed the errors that university students made when performing subtraction. A 20-subtraction questionnaire was used as the instrument. The sample included university students from three different centres: teaching, business and statistics. The sex, age, centre, year, type of study completed prior to arrival at the university and time taken to complete the questionnaire were taken into consideration. The results were compared with the errors made by primary students.

In this context, the main conclusions of this research are as follows: 
- Only one quarter of university students correctly answered all 20 subtractions in the questionnaire they completed. Extending the criteria for successful completion of the questionnaire to admit up to two errors resulted in only two thirds of students completing the questionnaire correctly.

- There were significant differences related to the level of success in completing the questionnaire depending on the students' sex (in favour of women), centre of studies (in favour of teaching students compared to business and statistics students) and time taken to complete the questionnaire (in favour of those who took fewer than five minutes, as against those who took longer than five minutes). There were no significant differences in terms of successful completion of the questionnaire based on age, year or previous studies.

- The typology of the most frequently occurring errors committed by university students, which essentially coincides with the profile for primary students, indicates that in addition to these errors corresponding to a deficient handling of basic numerical relationships, they were also due to weaknesses in understanding zero and the place value system.

It is not easy to understand how university students can commit so many errors when performing subtraction, and whether subtraction is really an operation that is fundamental to their future lives as professionals and citizens. The findings of this study appear to show an absence of number sense and critical thinking among university students—or at least that this is an aspect where there is room for improvement. The teaching and learning of subtraction at primary ages should be aimed in this direction, perhaps as well as those of other basic maths, where the aim is not merely to achieve mechanical algorithmic learning but also to develop constructive, critical and reflective thinking; this would permit the opening up of various lines of research.

Despite teaching diploma students being the group that committed fewest errors in this study, their results are particularly concerning given that they will be the teachers with responsibility for the teaching and learning of subtraction in primary school classrooms. If they have not mastered their understanding of zero and the place value system, it will be difficult for them to be able to work adequately in a primary school classroom and this may mean that they are limited to teaching on a rote basis by using a set of rules that will probably be given in a textbook. It may therefore be useful to take into account the possibility of addressing this in the undergraduate curriculum for this university qualification, in order to construct a more critical and reflective form of learning.

Author Contributions: Conceptualisation, M.M.R.-S., A.B.S.-G. and R.L.-F.; data curation, M.M.R.-S. and A.B.S.-G.; formal analysis, M.M.R.-S.; investigation, M.M.R.-S., A.B.S.-G. and R.L.-F.; methodology, M.M.R.-S. and A.B.S.-G.; supervision, M.M.R.-S., A.B.S.-G. and R.L.-F.; validation, M.M.R.-S., A.B.S.-G. and R.L.-F.; writing-original draft, M.M.R.-S.; writing-review and editing, M.M.R.-S., A.B.S.-G. and R.L.-F. All authors have read and agreed to the published version of the manuscript.

Funding: This research received no external funding.

Acknowledgments: This work was partially supported by Ministry of Education of Castilla y León, Spain (Project: SA050G19).

Conflicts of Interest: The authors declare no conflict of interest.

\section{References}

1. Chamoso, J.M. Considering dialogue as a social instrument in the Mathematics class. Learn. Math. 2003, 23, 30-40.

2. NCTM (National Council of Teachers of Mathematics). Principles and Standards for School Mathematics; NCTM: Reston, VA, USA, 2000.

3. Voigt, J. Negotiation of mathematical meaning and learning mathematics. Educ. Stud. Math. 1994, 26, $275-298$. [CrossRef]

4. Jimenez, L.; Verschaffel, L. Development of Children's solutions of non-standard arithmetic word problem solving. Rev. Psicodidact. 2014, 19, 93-123. [CrossRef]

5. Depaepe, F.; De Corte, E.; Verschaffel, L. Teachers' approaches towards word problem solving: Elaborating or restricting the problem context. Teach. Teach. Educ. 2010, 26, 152-160. [CrossRef] 
6. Kolovou, A.; Van den Heuvel-Panhuizen, M.; Bakker, A. Non-routine problem solving tasks in Primary School Mathematics textbooks-a needle in a Haystack. Mediterr. J. Res. Math. Educ. 2009, 8, 31-68.

7. Reusser, K.; Stebler, R. Every word problem has a solution-The social rationality of mathematical modeling in schools. Learn. Instr. 1997, 7, 309-327. [CrossRef]

8. Resnick, L.B. Education and Learning to Think; National Academic Press: Washington, DC, USA, 1987.

9. Carpenter, T.P.; Franke, M.L.; Jacobs, V.R.; Fennema, E. Invention and Understanding in the Development of Multidigit Addition and Subtraction Procedures: A Longitudinal Study. In Proceedings of the Annual Meeting of the American Educational Research Association, New York, NY, USA, 8-12 April 1996.

10. Fuson, K. Roles of representation and verbalization in the teaching of multi-digit addition and subtraction. Eur. J. Psychol. Educ. 1986, 1, 35-56. [CrossRef]

11. Fuson, K.C.; Briars, D.J. Using a base-ten blocks learning/teaching approach for first -and second-grade place- value and multidigit addition and subtraction. J. Res. Math. Educ. 1990, 21, 180. [CrossRef]

12. Hiebert, J.; Wearne, D. Instruction, understanding, and skill in multidigit addition and subtraction. Cogn. Instr. 1996, 14, 251-283. [CrossRef]

13. Resnick, L.B. Syntax and semantics in learning to subtract. In Addition and Subtraction: A Developmental Perspective; Carpenter, T., Moser, J., Romberg, T., Eds.; Lawrence Erlbaum Assoc: Hillsdale, NJ, USA, 1982.

14. Resnick, L.B.; Omanson, S.F. Learning to understand arithmetic. In Advances in Instructional Psychology; Glaser, R., Ed.; Lawrence Erlbaum Assoc: Hillsdale, NJ, USA, 1987.

15. Sánchez-García, A.B. Algorithmic Errors. Cognitive Processes and Educational Actions. Teor. Educ. Rev. Interuniv. 2013, 25, 215-235.

16. VanLehn, K. Mind Bugs: The Origins of Procedural Misconceptions; The MIT Press: Cambridge, MA, USA, 1990.

17. Engberg, M.E.; Wolniak, G.C. College student pathways to the STEM disciplines. Teach. Coll. Rec. (1970) 2013, 115, 1-27.

18. Jordan, N.C.; Kaplan, D.; Ramineni, C.; Locuniak, M.N. Early math matters: Kindergarten number competence and later mathematics outcomes. Dev. Psychol. 2009, 45, 850-867. [CrossRef] [PubMed]

19. Geary, D.C. Consequences, characteristics, and causes of mathematical learning disabilities and persistent low achievement in mathematics. J. Dev. Behav. Pediatr. 2011, 32, 250-263. [CrossRef] [PubMed]

20. Lefevre, J.-A.; Bisanz, J.; Daley, K.E.; Buffone, L.; Greenham, S.L. Multiple routes to solution of single-digit multiplication problems. J. Exp. Psychol. Gen. 1996, 125, 284-306. [CrossRef]

21. Mitchell, J.H.; Hawkins, E.F.; Stancavage, F.B.; Dossey, J.A. Estimation Skills, Mathematics-in-Context, and Advanced Skills in Mathematics: Results from Three Studies of the National Assessment of Educational Progress 1996 Mathematics Assessment; Education Publications Center (Ed Pubs): Washington, DC, USA, 1999.

22. Ohlsson, S.; Rees, E. The function of conceptual understanding in the learning of arithmetic procedures. Cogn. Instr. 1991, 8, 103-179. [CrossRef]

23. Chamoso, J.; González, S.; Martín, P.; Hernández, R.W. Las Matemáticas en Las Primeras Edades Escolares; Colección Diálogos de Matemáticas, Nivola: Madrid, Spain, 2013.

24. Baroody, A.J. Children's Mathematical Thinking: A Developmental Framework for Preschool, Primary, and Special Education Teachers; Teachers College Press: New York, NY, USA, 1987.

25. Hughes, M. Children and Number: Difficulties in Learning Mathematics; Blackwell Publishing: Oxford, UK, 1986.

26. Starkey, P.; Cooper, R.G. Perception of numbers by human infants. Science 1980, 210, 1033-1035. [CrossRef]

27. Ginsburg, H.P.; Klein, A.; Starkey, P. The development of children's mathematical thinking: Connecting research with practice. In Handbook of Child Psychology, 5th ed.; Damon, W., Sigel, I.E., Renninger, K.A., Eds.; Wiley and Sons: Hoboken, NJ, USA, 1998; Volume 4, pp. 401-476.

28. Cooper, T.J.; Heirdsfield, A.; Irons, C.J. Children's mental strategies for addition and subtraction word problems. In Children's Number Learning; Mulligan, J.J., Mitchelmore, M., Eds.; Australian Association of Mathematics Teachers, Inc. (AAMT): Adelaide, Australia, 1996; pp. 147-162.

29. Klein, A.S.; Beishuizen, M.; Treffers, A. The empty number line in Dutch second grades: Realistic versus gradual program design. J. Res. Math. Educ. 1998, 29, 443-464. [CrossRef]

30. Fuson, K.C.; Wearne, D.; Hiebert, J.C.; Murray, H.G.; Human, P.G.; Olivier, A.I.; Carpenter, T.P.; Fennema, E. Children's conceptual structures for multidigit numbers and methods of multidigit addition and subtraction. J. Res. Math. Educ. 1997, 28, 130-162. [CrossRef] 
31. Brownell, W.A. Psychological considerations in the learning and teaching of arithmetic. In The Teaching of Arithmetic; Reeve, D.W., Ed.; Bureau of Publications, Teachers College, Columbia University: New York, NY, USA, 1935; pp. 1-31.

32. Groen, G.; Resnick, L.B. Can preschool children invent addition algorithms? J. Educ. Psychol. 1977, 69, 645-652. [CrossRef]

33. Brown, J.S.; Burton, R.R. Diagnostic Models for Procedural Bugs in Basic Mathematical Skills. Cogn. Sci. 1978, 2, 155-192. [CrossRef]

34. Gagne, R.M. The Conditions of Learning; Holt, Rinehart \& Winston: New York, NY, USA, 1970.

35. Woods, P.; Hartley, J.R. Some learning models for arithmetic tasks and their use in computer based learning. Br. J. Educ. Psychol. 1971, 41, 38-48. [CrossRef]

36. Woods, S.S.; Resnick, L.B.; Groen, G.J. An Experimental Test of Five Process Models for Subtraction. J. Educ. Psychol. 1975, 67, 17-21. [CrossRef]

37. Lankford, F.G. Some Computational Strategies of Seventh Grade Pupils; University of Virginia: Charlottesville, VA, USA, 1972.

38. Ashlock, R.B. Error Patterns in Computation; Charles, E., Ed.; Merrill Publishing Co.: Columbus, OH, USA, 1976.

39. Newell, A.; Simon, H.A. Human Problem Solving; Prentice-Hall: Englewood Cliffs, NJ, USA, 1972.

40. Anderson, J.R. Language, Memory, and Thought; Lawrence Erlbaum Associates: Hillsdale, NJ, USA, 1976.

41. Young, R.M.; O'Shea, T. Errors in Children's Subtraction. Cogn. Sci. 1981, 2, 153-177. [CrossRef]

42. Young, R.M. Seriation by Children: An Artificial Intelligence Analysis of a Piagetian Task; Birkhauser: Basel, Switzerland, 1976.

43. Young, R.M. Mixtures of strategies in structurally adaptive production systems: Examples from seriation and subtraction. ACM SIGART Bull. 1977, 63, 65-71. [CrossRef]

44. Brown, J.S.; VanLehn, K. Repair Theory: A generative theory of bugs in procedural skills. Cogn. Sci. 1980, 4, 379-426. [CrossRef]

45. Brown, J.S.; Vanlehn, K. Towards a generative theory of "bugs". In Addition and Subtraction: A Cognitive Perspective; Carpenter, T.P., Moser, J.M., Romberg, T.A., Eds.; Lawrence Erlbaum Associates: Hillsdale, NJ, USA, 1982; pp. 117-135. [CrossRef]

46. VanLehn, K. Bugs are not enough: Empirical studies of bugs, impasses and repairs in procedural skills. J. Math. Behav. 1982, 3, 3-71.

47. Fuson, K.C. Research on Whole Number Addition and Subtraction. In Handbook of Research on Mathematics Teaching and Learning: A Project of the National Council of Teachers of Mathematics; Grouws, D.A., Ed.; Macmillan Publishing Co.: New York, NY, USA, 1992; pp. 243-275.

48. Verschaffel, L.; De Corte, E. Number and arithmetic. In International Handbook of Mathematics Education; Bishop, A.J., Clements, K., Keitel, C., Kilpatrick, J., Laborde, C., Eds.; Kluwer Academic Publishers: New York, NY, USA, 1996; pp. 99-137.

49. Bélanger, M. Les erreurs en arithmétique. Un siècle de présomption méricaine. Petit X 1991, 26, 49-71.

50. Ashcraft, M.H. Cognitive arithmetic: A review of data and theory. Cognition 1992, 44, 75-106. [CrossRef]

51. López-Fernández, R.; Sánchez-García, A.B. Los componentes generadores de errores algorítmicos. Caso particular de la sustracción. Rev. Educ. 2007, 344, 377-402.

52. López-Fernández, R.; Sánchez-García, A.B. Analysis of systematic error in substraction. Enseñ. Cienc. 2009, 27, 49-58.

53. Cox, L.S. Systematic errors in the four vertical algorithms in normal and handicapped populations. J. Res. Math. Educ. 1975, 6, 202-220. [CrossRef]

54. Bennett, M. SUBSTITUTOR: A Teaching Program; Department of Artificial Intelligence, University of Edinburgh: Edinburgh, UK, 1976; Unpublished Project Report.

55. Cebulski, L.A.; Bucher, B. Identification and remediation of children's subtraction errors: A comparison of practical approaches. J. Sch. Psychol. 1986, 24, 163-180. [CrossRef]

56. Sander, E. Solving arithmetic operations: A semantic approach. In Proceedings of the 23rd Annual Conference of the Cognitive Science Society, Edinburgh, UK, 1-4 August 2001; Moore, J.D., Stenning, K., Eds.; Lawrence Erlbaum Associates, Inc.: Mahwah, NJ, USA, 2001; pp. 915-920.

57. Fiori, C.; Zuccheri, L. An experimental research on error patterns in written subtraction. Educ. Stud. Math. 2005, 60, 323-331. [CrossRef] 
58. Barrouillet, P.; Fayol, M. From algorithmic computing to direct retrieval: Evidence from number and alphabetic arithmetic in children and adults. Mem. Cognit. 1998, 26, 355-368. [CrossRef]

59. Geary, D.C.; Frensch, P.A.; Wiley, J.G. Simple and Complex Mental Subtraction: Strategy Choice and Speed-of-Processing Differences in Younger and Older Adults. Psychol. Aging 1993, 8, 242-256. [CrossRef]

60. Creswell, J.W. Research Design: Qualitative, Quantitative, and Mixed Methods Approaches; Sage: London, UK, 2008.

61. McMillan, J.H.; Schumacher, S. Research in Education: A Conceptual Introduction, 5th ed.; Addison Wesley Longman: New York, NY, USA, 2001.

62. Kramarski, B.; Mevarech, Z.R.; Arami, M. The Effects of Metacognitive Instruction on Solving Mathematical Authentic Tasks. Educ. Stud. Math. 2002, 49, 225-250. [CrossRef]

63. Polya, G. Como Plantear and Resolver Problemas; Trillas: México DF, México, 1965.

64. Baroody, A.J. Kindergartners' mental addition with single-digit combinations. J. Res. Math. Educ. 1989, 20, 159-172. [CrossRef]

65. Cobb, P.; Wheatley, G. Children's Initial Understandings of Ten. Focus Learn. Probl. Math. 1988, 10, 1-28.

66. Cobb, P.; Yackel, E.; Wood, T.; Wheatley, G.; Merkel, G. Creating a problem-solving atmosphere. Arith. Teach. 1988, 36, 46-47.

67. Kamii, C.; Lewis, B.A. Achievement Tests in Primary Mathematics: Perpetuating Lower-Order Thinking. Arith. Teach. 1991, 38, 4-9. [CrossRef]

68. Carraher, T.N.; Carraher, D.W.; Schliemann, A.D. Mathematics in the streets and in schools. Br. J. Dev. Psychol. 1985, 3, 21-29. [CrossRef]

Publisher's Note: MDPI stays neutral with regard to jurisdictional claims in published maps and institutional affiliations.

(C) 2020 by the authors. Licensee MDPI, Basel, Switzerland. This article is an open access article distributed under the terms and conditions of the Creative Commons Attribution (CC BY) license (http://creativecommons.org/licenses/by/4.0/). 